\title{
STUDY ON ANTIBACTERIAL EFFECTS OF SEVERAL VIETNAMESE MEDICINE PLANTS AND THEIR RELATIONSHIPS WITH POLYPHENOL CONTENTS
}

\author{
THANH VAN NGUYEN ${ }^{1 *}$, HAI THANH NGUYEN ${ }^{2}$ \\ ${ }^{1}$ Department of Veterinary Surgery and Reproduction, Faculty of Veterinary Medicine, Vietnam National University of Agriculture, Trau \\ Quy, Gia Lam, Hanoi, Vietnam, ${ }^{2}$ Department of Plant Bio-Technology, Faculty of Biotechnology, Vietnam National University of Agriculture, \\ Trau Quy, Gia Lam, Hanoi, Vietnam. *Email: nvthanh54@gmail.com \\ Received: 30 January 2019, Revised and Accepted: 15 March 2019
}

ABSTRACT

Objective: Our study evaluated the inhibitory effects of 13 plant materials on bacterial growth, so as to explain their traditional uses in bacterial infections. In addition, the correlation between antibacterial effects of plants and the polyphenol contents or antioxidant activities was also verified to investigate if these properties were responsible for the plant antibacterial effects.

Methods: We tested extracts with 20 bacterial strains purchased from Japan Veterinary Products Association (JVPA, Tokyo, Japan) and also the Escherichia coli (E. coli) and Streptococcus suis (S. suis) strains that we had previously isolated from livestock. After polyphenol contents and antioxidant activities were measured, we examined their correlations with antibacterial effects.

Results: The results showed that all extracts exerted inhibitory effects on tested bacteria and at different levels. Among all of samples, betel and mother rhizome of turmeric showed the strongest effects and also exerted inhibition on antibiotic-resistant $E$. coli and $S$. suis bacteria. In addition, direct and significant correlations between antibacterial effects' and polyphenol content's values were established and thus demonstrating that antibacterial effects of plants were attributable, at least in part, to the presence of polyphenol compounds.

Conclusions: Our study demonstrated the antibacterial effects of 13 plant materials and, therefore, partly gives pharmacological basis to explain their traditional uses in diseases associated with bacterial infections. In addition, as betel and mother rhizome of turmeric showed the highest effects, we suggested that they might serve as the most promissory candidates for bacterial treatment. However, follow-up researches are still required to assess their potentials.

Keywords: Medicinal plant, Antibacterial effect, Polyphenol content, Antioxidant activity, Betel, Turmeric, Mother rhizome.

(c) 2019 The Authors. Published by Innovare Academic Sciences Pvt Ltd. This is an open access article under the CC BY license (http://creativecommons. org/licenses/by/4. 0/) DOI: http://dx.doi.org/10.22159/ajpcr.2019.v12i4.32290

\section{INTRODUCTION}

The appearance of antibiotic resistance has become a global concern, and there is a continuous and urgent need to discover new antimicrobial compounds with diverse chemical structures and novel mechanisms of action to replace antibiotics in the treatment of bacterial infections [1]. According to Mahesh and Satish [2], plants are a rich source of antimicrobial agents and many of them have been found effective in the cure of bacterial diseases. In addition, medicinal plants are believed to have less side effects, less residues, slower resistance and might also induce the enhancement in the growth and survival rates of host animals [3]. In this study, we investigated antibacterial effects of 13 medicinal plants. We selected to test these plant materials because traditional herbalism has suggested their potent antimicrobial property and/or they have been traditionally employed to treat diseases that associated with bacterial infections [4a-g, 5a-k, 6]. Plant extracts were first tested with 12 bacterial strains including six Gram-positive and six Gram-negative bacteria purchased from Japan Veterinary Products Association (JVPA, Tokyo, Japan), to evaluate their antibacterial effects through the determination of the minimum inhibitory concentration (MIC) values. Extracts that showed high inhibition on bacterial growth were later tested with Escherichia coli (E. coli) and Streptococcus suis (S. suis) strains isolated from livestock to further evaluate their inhibitory potentials. Along with MIC determination, our study also measured polyphenol contents and antioxidant activities of extracts and investigated their relationships with antibacterial effects because these values had been reported to associate with antimicrobial properties of plants $[7,8]$. In addition, because not only antibacterial effects but also many other pharmacological functions and health improvement of plants are attributed to polyphenol contents and/or antioxidant activities [9]; determination on these values is certainly useful to assess their biological properties.

\section{MATERIALS AND METHODS}

\section{Collection and extraction of plant materials}

Plants were supplied by the Department of Internal Medicine and Pharmacology, Faculty of Veterinary Medicine, Hanoi National University of Agriculture, Vietnam. The plants in scientific, English and local names, along with their collected parts are shown in Table 1. Their identity was confirmed by Dr. Tho Thi Bui based on voucher specimens that had been deposited at Vuon Duoc Lieu Thu Y Herbarium, Vietnam National University of Agriculture in Vietnam. In our study, we separated turmeric to mother and first daughter rhizome to investigate because traditional medicine practitioners in Vietnam had observed the differences in their treatment effects with some diseases including those were associated with bacterial infections [10]. Fresh plant materials were washed under running tap water, preliminarily dried in the shadow from 3 to 4 days before being dried at $50^{\circ} \mathrm{C}$ for $3 \mathrm{~h}$ in a constant temperature oven (DK63, Yamayo, Japan). Dried materials were then pulverized into fine powder with the particle size $<1 \mathrm{~mm}$ before extraction. In brief, $10 \mathrm{~g}$ of each sample was stirred for $30 \mathrm{~m}$ in $200 \mathrm{~g}$ of organic solvents such as absolute ethanol (Cica Reagent, Kanto Chemical Co., Inc., Japan) or methanol (Wako, Osaka, Japan). Extracts were then put in a shaking water bath with the temperature of $40^{\circ} \mathrm{C}$ for $2 \mathrm{~h}$ and filtered with No. 2 qualitative paper (Advantec MFS Inc., Dublin, CA, USA). The filtrates were concentrated at $40^{\circ} \mathrm{C}$ using a rotary evaporator at low atmosphere pressure (Buchi Rotavapor R-210, Switzerland). After condensed, each 
Table 1: List of plant materials

\begin{tabular}{llll}
\hline No. & English name (Abbreviation) & Latin name & Collected parts \\
\hline 1 & Basil & Ocimum basilicum & Leaves \\
2 & Betle & Piper betle & Leaves \\
3 & Dill Nepali & Anethum graveolens & Aerial parts \\
4 & Indian camphorweed & Pluchea indica & Eryngium foetidum \\
5 & Shadon & Paederia tomentosa & Leaves \\
6 & Skunk-vine & Plantago major & Leaves \\
7 & Greater plantain & Artemisia vulgaris \\
8 & Mugwort & Zinger zerumbet & Aerial parts \\
9 & Shampoo zinger & Sphagneticola trilobata \\
10 & Singapore daisy & Curcuma longa & Tubes \\
11 & Turmeric - mother rhizomes & & Leaves \\
& Turmeric - first daughter rhizomes & Pseuderanthemum variabile \\
\hline
\end{tabular}

extract was dissolved in $10 \mathrm{ml}$ dimethylsulfoxide ([DMSO], Nacalai Tesque, Kyoto, Japan) to make solutions at the concentration of $1000 \mathrm{mg}$ dried material/ml (this concentration was calculated based on the weight of crude plant materials used for extraction). After passing through $0.2 \mu \mathrm{l}$ pore sized filter (DISMIC-13JP syringe filter, Toyo Roshi Kaisha, Tokyo, Japan) for sterilization, filtrates were used as the starting solutions in all experiments. Extraction was performed twice with every plant material to obtain two independent extracts from each sample. The measurements, including the MIC, polyphenol contents, and antioxidant activities, were performed with these two independent extracts and in duplication for each extract.

\section{Bacterial strains}

Twelve commercial bacteria, such as E. coli (E. coli, three strains: ML 1409 K-12, BSE4001, and JC strains), Lactobacillus fermentum (L. fermentum, NBRC 3961), Lactobacillus acidophilus (L. acidophilus, American Type Culture Collection [ATTC, USA] 4356), Lactobacillus bulgaricus (L. bulgaricus, ATTC 11842), Streptococcus thermophilus (S. thermophilus, ATTC 14485), Pseudomonas aeruginosa (P. aeruginosa, KK-1001, BPP 0501), Staphylococcus aureus (S. aureus, KK-103, BBS 1001), Streptococcus suis (S. suis, S-9, BSS4001), Campylobacter jejuni (C. jejuni, KK-1020, BBC 020), and Salmonella infantis (S. infantis, L164, BAS 290), were purchased from JVPA, Tokyo, Japan. To obtain fresh colonies that required for the determination of MIC, each bacterium was subcultured into the appropriate agar and in suitable condition, followed the instructions of the provider (JVPA, Japan). In addition, we also used nine isolates of $E$. coli from chicken and 23 isolates of $S$. suis from pigs. Those bacterial strains were preserved in the laboratory and their phenotypes of resistance to antimicrobials had been identified by the previous studies, as shown in the "supplemental material."

\section{Media preparation and MIC determination}

The MICs of plant extracts to bacteria were determined employing the microbroth dilution method. Cation-adjusted Mueller-Hinton broth was used for bacteria isolated from animals [11] and anaerobe broth MIC was used for anaerobic bacteria [12]. Plant extract-containing broth for susceptibility determination was prepared with 96-well microplates. The starting solutions of extracts starting from $1000 \mathrm{mg} / \mathrm{ml}$ were diluted with broths to make the 2 -fold dilution range that included the concentrations of $500,250,125,62.5,31.3,15.6,7.8$, and $3.9 \mathrm{mg} / \mathrm{ml}$. The final volume for each well was $100 \mu \mathrm{l}$. To confirm that DMSO contained in extract starting solutions itself had no effects on bacterial growth, the controls were also made using the pure DMSO which contained no plant extracts. The final concentration of bacteria isolated from animals, including E. coli (ML 1409 K-12, BSE4001, JC strains from JVPA, and nine strains isolated from chicken), P. aeruginosa (KK-1001, BPP 0501), S. aureus (KK-103, BBS 1001), S. suis (S-9, BSS4001 strain from JVPA, and 23 strains isolated from pigs), C. jejuni (KK-1020, BBC 020), and $S$. infantis (L164, BAS 290), was adjusted to $5 \times 10^{4} \mathrm{cfu} /$ well and incubated for $24 \mathrm{~h}$ in ambient condition [10]. For anaerobic bacteria including L. fermentum (NBRC 3961), L. acidophilus (ATTC 4356),
L. bulgaricus (ATTC 11842), and S. thermophilus (ATTC 14485), the final concentration was adjusted to $10^{5} \mathrm{cfu} /$ well and incubated for $48 \mathrm{~h}$ in anaerobic condition [12]. Results were observed with the aid of an inverted reading mirror, and the lowest concentration that inhibited the growth of bacterium compared to that of the control was determined as the MIC value.

Measurement of polyphenol contents and antioxidant activities Polyphenol contents and antioxidant activities were measured employing Folin-Ciocalteu and 1,1-diphenyl-2-picrylhydrazyl (DPPH) assays, respectively, following the methods of Masuda et al. [13] and with some modifications. The starting solutions of extracts were diluted for 10 times by DMSO to obtain the concentration of $100 \mathrm{mg} / \mathrm{ml}$ before measuring polyphenol contents and DPPH scavenging activities.

\section{Folin-Ciocalteu assay for total phenolic contents}

In brief, the control contained $1 \mathrm{ml}$ of Folin-Ciocalteu (Nacalai Tesque, Kyoto, Japan) reagent and $0.2 \mathrm{ml}$ of plant extract. This mixture was allowed to stand at room temperature for $3 \mathrm{~min}$. Then, $1 \mathrm{ml}$ of $10 \%$ $\mathrm{Na}_{2} \mathrm{CO}_{3}$ (Nacalai Tesque, Kyoto, Japan) and $5 \mathrm{ml}$ of distilled water were added. After $1 \mathrm{~h}$ of incubation in the dark at room temperature, the absorbance was measured using a spectrophotometer (ERMA model AE450 , Japan) at $750 \mathrm{~nm}$. The sample without Folin-Ciocalteu reagent was taken as the blank. Chlorogenic acid (Sigma-Aldrich Co., LLC, USA) was used as a standard and results were expressed as mg chlorogenic acid equivalents per $\mathrm{g}$ of dried sample (mg chlorogenic acid/g dried matter).

\section{DPPH assay for antioxidant activities}

DPPH working solution was made by mixing $0.1 \mathrm{~g}$ DPPH powder with $50 \mathrm{ml}$ ethanol $96 \%$. Briefly, $0.2 \mathrm{ml}$ sample was added to $0.1 \mathrm{ml} \mathrm{DPPH}$ working solution and $4.8 \mathrm{ml}$ solvent. After shaking, this mixture was left to react in a dark and at room temperature for $30 \mathrm{~min}$. Control contained $0.1 \mathrm{ml}$ DPPH solution and $4.9 \mathrm{ml}$ solvent, while blank contained $0.2 \mathrm{ml}$ sample and $4.8 \mathrm{ml}$ solvent. Absorbance was measured at $515 \mathrm{~nm}$. The scavenging activity was calculated as follows: DPPH scavenging activity $(\%)=([\mathrm{Ac}-\mathrm{As}-\mathrm{Ab}] / \mathrm{Ac}) \times 100$; where, Ac=Control absorbance, As=Sample absorbance, and Ab=Blank absorbance. Trolox (6-hydroxy2,5,7,8-tetra-methyl-chroman-2-carboxylic acid) (Calbiochem, USA) was used as a standard and results were expressed as mg of Trolox equivalents per g of dried sample (mg Trolox/g dried matter).

\section{Statistical analysis}

Data were expressed as mean \pm standard error (Mean \pm SE). Two-factor ANOVA followed by post hoc Bonferroni test was used to compare MICs of different extracts. One-way ANOVA followed by post hoc Bonferroni test was used to compare polyphenol contents and antioxidant activities of different extracts. Student's $t$-test was used to compare MICs of extracts from different solvents (ethanol and methanol) or MICs of different extracts (betel and turmeric mother rhizome) to E. coli or S. suis bacteria. Linear regressions from (-MICs), polyphenol contents, 
and antioxidant activities were computed and Pearson's correlation coefficient test was used to evaluate their correlations. In all analysis, significance was established when probability level was $\leq 5 \%(\mathrm{p}<0.05)$.

\section{RESULTS}

Antibacterial effects of plant extracts to 12 JVPA bacterial strains We observed that all of plant extracts showed different levels of inhibitory effects on the bacterial growth of 12 JVPA bacteria, in which the determined MICs were various from 3.9 to $125.0 \mathrm{mg} / \mathrm{ml}$ (data not shown). To access the difference in antibacterial effects of tested plant materials, we compared their MICs to Gram-positive or Gram-negative bacteria, and results are shown in Fig. 1. For Gram-positive bacteria, we observed that among all of ethanol extracts, betel, turmeric mother rhizome, and Wedelia had the strongest inhibition, as they exerted the lowest MICs (Fig. 1A), while among all of methanol extracts, betel, Indian camphorweed, turmeric mother rhizome, and Wedelia had the strongest inhibition and showed the lowest MICs (Fig. 1B). For Gram-negative bacteria, the strongest effects of betel and turmeric mother rhizome among all ethanol extracts and the strongest effects of betel among all methanol extracts were evident by their lowest MICs (Figs. 1C and 1D). When considering the effects with both Gramnegative and Gram-positive bacteria together, the strongest effects belonged to betel and turmeric mother rhizome, because regardless of bacterial grams, these two materials always exerted the lowest MICs and thus demonstrating the highest inhibitory effects. In the respect to different plant materials, we also observed that turmeric mother rhizome had stronger inhibition than turmeric first daughter rhizome because the former showed significant lower MICs to both of Gram-positive (Figs. 1A and 1B) and Gram-negative bacteria (Figs. 1C and 1D). In respect to sensitivity of different bacteria, we compared means of MICs of extracts with each bacterium, and results are shown in Fig. 2. We observed that among all bacteria, E. coli (BSE) showed the strongest resistance, while L. fermentum showed the highest sensitivity to plant extracts. In addition, Gram-negative bacteria were generally more resistant than Gram-positive bacteria. We observed that among six tested Gram-negative bacteria, four of them had significantly higher MICs than those of all six Gram-positive bacteria, while other two exceptions: E. coli (ml) and C. jejuni exerted the MICs that not significantly different to those of Gram-positive bacteria. In respect to the effects of different extracting solvents, we compared the means of MICs of the ethanol extracts to those of methanol extracts, as shown in Fig. 3. We observed that mean of MICs from methanol extracts to six Gram-negative bacteria was significantly lower than that from ethanol extracts, thus indicating that methanol extracts had stronger inhibition on Gram-negative bacteria. However, difference between the two solvents was not observed with Gram-positive bacteria.

Antibacterial effects of betel and turmeric mother rhizome extracts to $E$. coli and $S$. suis strains isolated from livestock

Means of MICs of betel and turmeric mother rhizome extracts with nine E. coli and $23 \mathrm{~S}$. suis strains isolated from livestock are shown in Fig. 4. We observed that both of the plants showed inhibition effects with the two bacterial groups. Betel was more effective to $E$. coli than turmeric mother rhizome, because with both of ethanol and methanol extracts, the MICs of betel were significantly lower than the MICs of turmeric mother rhizome $(\mathrm{p}<0.01)$. In contrast, turmeric mother rhizome was more effective to $S$. suis than betel, because regardless of extracting solvents, the MICs of turmeric mother rhizome were significantly lower than the MICs of betel $(\mathrm{p}<0.01)$.

\section{POLYPHENOL CONTENTS, ANTIOXIDANT ACTIVITIES, AND THEIR CORRELATIONS WITH ANTIBACTERIAL EFFECTS}

Polyphenol contents and antioxidant activities of plant extracts are shown in Table 2. Betel and turmeric mother rhizome showed the highest polyphenol contents in ethanol extract group, and turmeric mother rhizome also showed the highest polyphenol content in methanol extract group. The highest antioxidant activities of ethanol extract group belonged to betel, greater plantain, turmeric first daughter rhizome, and turmeric mother rhizome, while the highest antioxidant activities

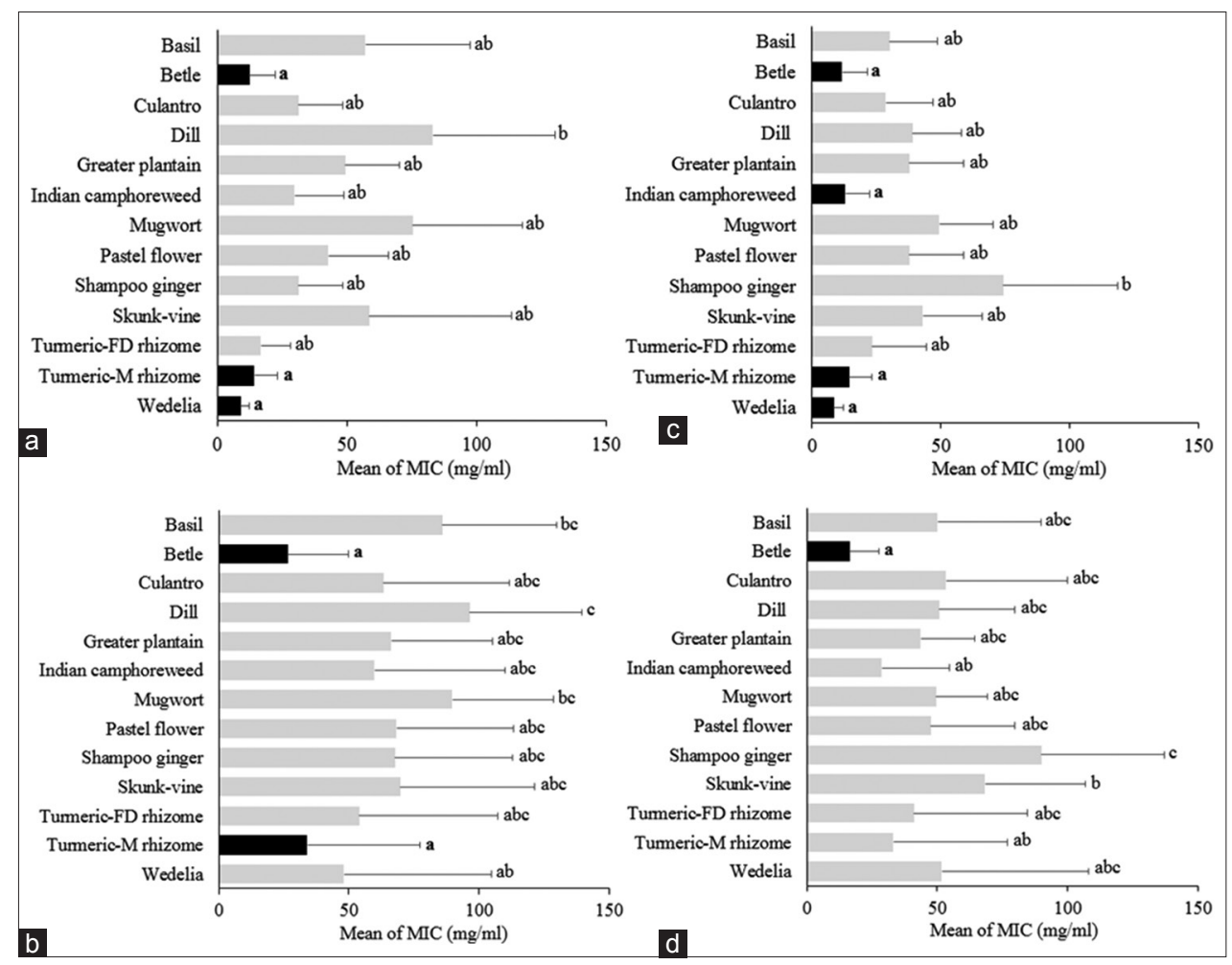

Fig. 1: Means of minimum inhibitory concentrations (MICs) of the extracts from different plants to [A, B] Gram-positive or [C, D] Gram-negative bacteria. Each value was mean of MICs of each extract to six Gram-positive or six Gram-negative bacteria. Means with different superscripts in each figure are significantly different $(p<0.05)$ by two-factor ANOVA followed by Bonferroni post hoc analysis. Black-filled column indicates plants of the lowest MIC values in each figure 
of methanol extract group belonged to cilantro, greater plantain, and turmeric first daughter rhizome. We also observed that regardless of extracting solvents, polyphenol contents of turmeric mother rhizome were always significantly higher than those of turmeric first daughter rhizome $(20.09 \pm 0.12$ vs. $6.32 \pm 0.31$ in ethanol extracts and $46.89 \pm 0.44$ vs. $6.83 \pm 0.007$ in methanol extracts). Turmeric mother rhizome also had significantly stronger antioxidant activities than first daughter rhizome in methanol extracts ( $8.42 \pm 0.09$ vs. $7.80 \pm 0.12)$, but there was no significant difference in ethanol extracts $(10.87 \pm 0.03$ vs. $10.34 \pm 0.05)$.

We also compared polyphenol contents and antioxidant activities from 13 ethanol extracts with those from 13 methanol extracts. Results showed that while the mean of polyphenol contents of methanol extracts was significantly higher than that of ethanol extracts $(\mathrm{p}<0.01$, Fig. 5), there was no significant difference observed between the antioxidant activities of the two groups (data not shown).

To determine the relationships between plant polyphenol contents and their antioxidant activities, we computed the linear regressions

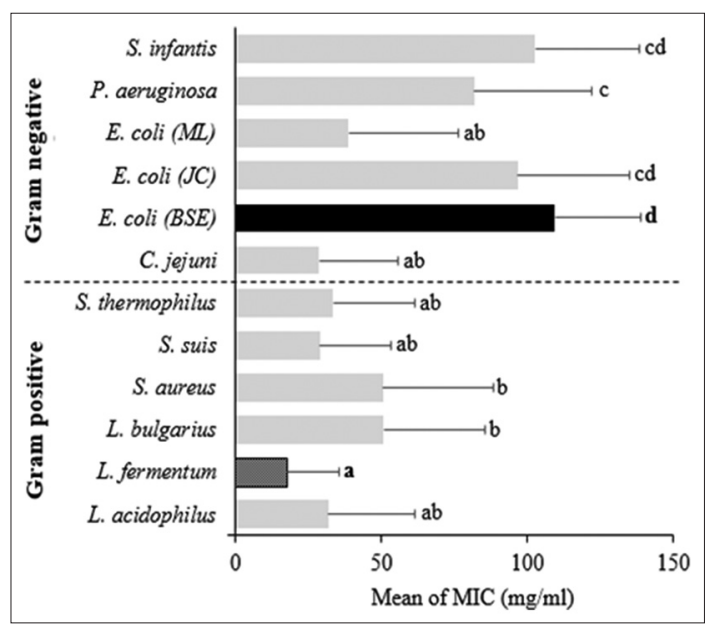

Fig. 2: Means of minimum inhibitory concentrations (MICs) of tested extracts to each bacterium. Each value was mean of MICs of 26 extracts. Means with different superscripts in each figure are significantly different $(p<0.05)$ by two-factor ANOVA followed by Bonferroni post hoc analysis. Black-filled column indicates the bacterium of the highest MIC value, while plaid column indicates the bacterium of the lowest MIC value

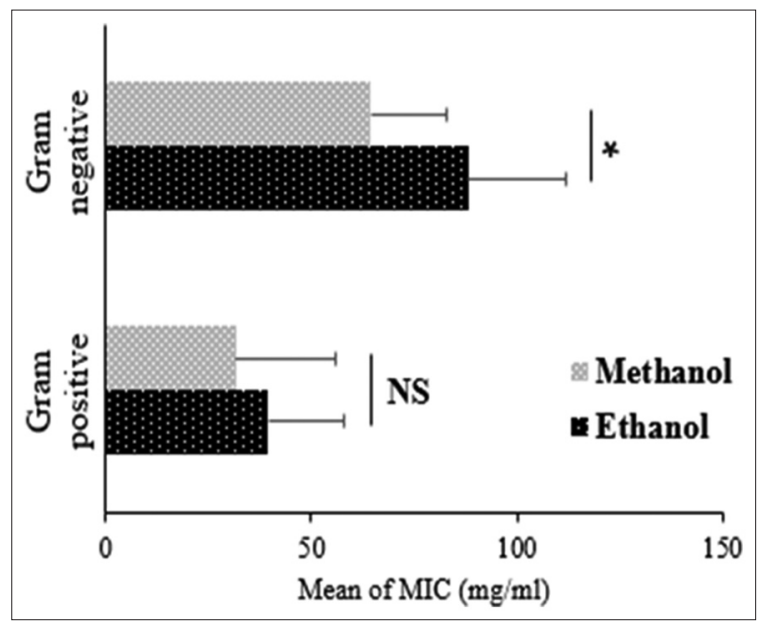

Fig. 3: Means of minimum inhibitory concentrations (MICs) from ethanol and methanol extracts to six Gram-positive and six Gram-negative bacteria. Each value was mean of MICs of 13 extracts. ${ }^{*}$ Significant different $(p<0.05)$ by Student's t-test. constructed from these two values and evaluated the correlations. Results showed that while polyphenol contents were positively and significantly correlated with antioxidant activities in ethanol extracts $(p<0.01$, Fig. $6 \mathrm{~A}$ ), there was no such kind of significant correlations in methanol extracts (data not shown). To determine the relationships between polyphenol contents or antioxidant activities with the plant antibacterial effects, we next computed the linear regressions constructed from values of polyphenol contents or antioxidant activities and means of -MICs, the values that represented effects of plants on bacteria. Results showed that, regardless of extracting solvents, there were always a positive and significant correlations between -MICs and polyphenol contents $(\mathrm{p}<0.01$ for ethanol extracts and $\mathrm{p}<0.05$ for methanol extracts, Fig. 6B-1 and 6B-2, respectively). However, the relationships between -MICs and antioxidant activities were less evident because their correlations were only positive and significant in ethanol extracts ( $\mathrm{p}<0.05$, Fig. $6 \mathrm{C})$, and there was no such kind of significant correlations in methanol extracts (data not shown).

\section{DISCUSSION}

All of extracts from tested plant materials showed various levels of inhibitory effects on different bacteria and thus providing

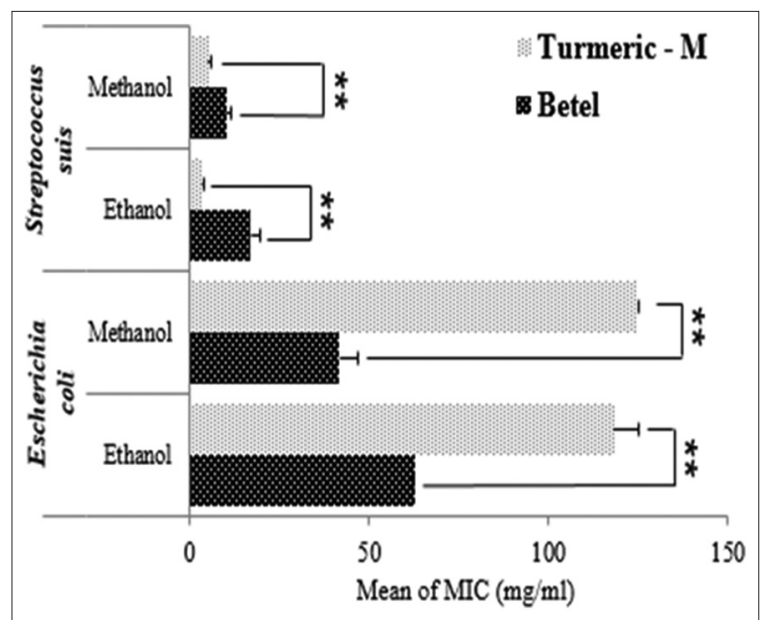

Fig. 4: Means of minimum inhibitory concentrations of ethanol and methanol extracts of betel and turmeric mother rhizome to nine Escherichia coli and 23 Streptococcus suis strains isolated from livestock. Turmeric-M means turmeric mother rhizome. **Significant difference, $\mathrm{p}<0.01$ by Student's $\mathrm{t}$-test

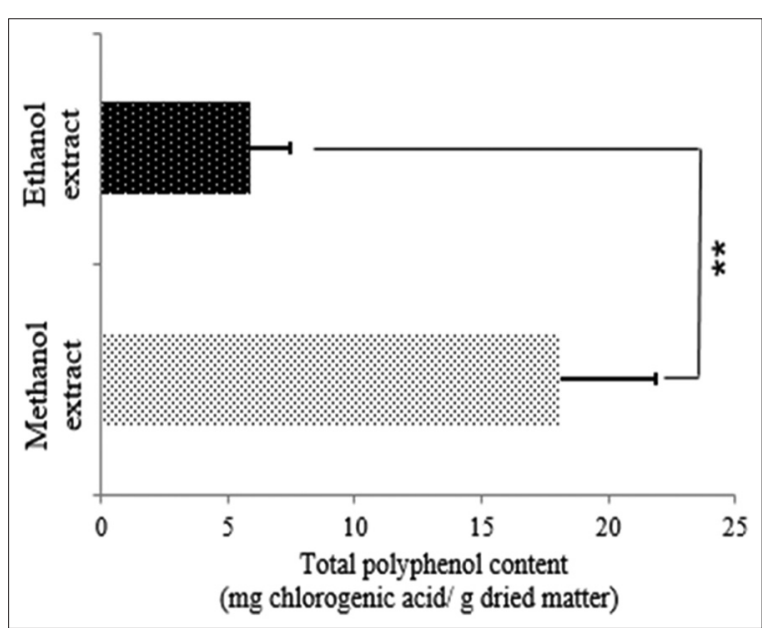

Fig. 5: Means of polyphenol content (mg chlorogenic acid/g dried matter) of 13 ethanol and 13 methanol extracts. Each value was mean of measurements from 13 extracts. ${ }^{* *}$ Significant difference, $p<0.01$ 
Table 2: Polyphenol contents (mg chlorogenic acid/g dried sample) and antioxidant activities (mg Trolox/g dried sample) of ethanol and methanol extracts diluted in DMSO

\begin{tabular}{|c|c|c|c|c|}
\hline \multirow[t]{2}{*}{ Herb } & \multicolumn{2}{|c|}{ Polyphenol content (mg chlorogenic acid/g dried sample) } & \multicolumn{2}{|c|}{$\begin{array}{c}\text { Antioxidant activity (mg Trolox/g dried } \\
\text { sample) }\end{array}$} \\
\hline & Ethanol & Methanol & Ethanol & Methanol \\
\hline Basil & $1.30 \pm 0.01^{\mathrm{j}}$ & $6.69 \pm 0.05^{j}$ & $8.22 \pm 0.11^{\mathrm{c}}$ & $8.32 \pm 0.09^{\mathrm{ab}}$ \\
\hline Betel & $18.6 \pm 0.02^{\mathrm{a}}$ & $27.56 \pm 0.08^{\mathrm{d}}$ & $10.69 \pm 0.06^{\mathrm{a}}$ & $7.06 \pm 0.14^{c}$ \\
\hline Culantro & $2.33 \pm 0.02^{\mathrm{i}}$ & $4.17 \pm 0.03^{\mathrm{k}}$ & $8.09 \pm 0.11^{c}$ & $8.51 \pm 0.08^{a}$ \\
\hline Dill & $1.62 \pm 0.03^{j}$ & $10.76 \pm 0.06^{\mathrm{h}}$ & $8.17 \pm 0.05^{\mathrm{c}}$ & $7.40 \pm 0.11^{\mathrm{b}}$ \\
\hline Greater plantain & $8.80 \pm 0.04^{c}$ & $20.81 \pm 0.06^{\mathrm{e}}$ & $10.77 \pm 0.04^{\mathrm{a}}$ & $8.54 \pm 0.11^{\mathrm{a}}$ \\
\hline Indian camphorweed & $2.89 \pm 0.16^{\mathrm{i}}$ & $29.81 \pm 0.05^{c}$ & $8.54 \pm 0.10^{c}$ & $7.22 \pm 0.13^{c}$ \\
\hline Mugwort & $5.57 \pm 0.02^{\mathrm{e}}$ & $16.84 \pm 0.05^{\mathrm{f}}$ & $9.96 \pm 0.06^{b}$ & $7.12 \pm 0.15^{c}$ \\
\hline Pastel flower & $4.72 \pm 0.01^{\mathrm{f}}$ & $13.33 \pm 0.10^{\mathrm{g}}$ & $9.17 \pm 0.08^{\mathrm{b}}$ & $7.94 \pm 0.11^{\mathrm{b}}$ \\
\hline Shampoo ginger & $4.09 \pm 0.02^{\mathrm{i}}$ & $4.48 \pm 0.08^{\mathrm{k}}$ & $8.14 \pm 0.10^{c}$ & $7.09 \pm 0.14^{c}$ \\
\hline Skunk-vine & $2.19 \pm 0.02^{j}$ & $9.25 \pm 0.01^{\mathrm{i}}$ & $8.40 \pm 0.10^{c}$ & $8.25 \pm 0.86^{\mathrm{ab}}$ \\
\hline $\begin{array}{l}\text { Turmeric - first daughter } \\
\text { rhizomes }\end{array}$ & $6.32 \pm 0.31^{\mathrm{d}}$ & $6.83 \pm 0.07^{i}$ & $10.34 \pm 0.05^{\mathrm{a}}$ & $8.42 \pm 0.09^{\mathrm{a}}$ \\
\hline Turmeric - mother rhizomes & $20.90 \pm 0.12^{\mathrm{a}}$ & $46.89 \pm 0.44^{\mathrm{a}}$ & $10.87 \pm 0.03^{\mathrm{a}}$ & $7.80 \pm 0.12^{\mathrm{b}}$ \\
\hline Wedelia & $13.48 \pm 0.06^{\mathrm{b}}$ & $37.63 \pm 0.02^{\mathrm{b}}$ & $9.54 \pm 0.08^{\mathrm{b}}$ & $7.16 \pm 0.13^{c}$ \\
\hline
\end{tabular}

Means with different superscripts in each column are significantly different $(\mathrm{p}<0.05)$ by one-way ANOVA followed by Bonferroni post hoc analysis. Number with bold letter indicates the highest values of each column. All values were mean of four measurements

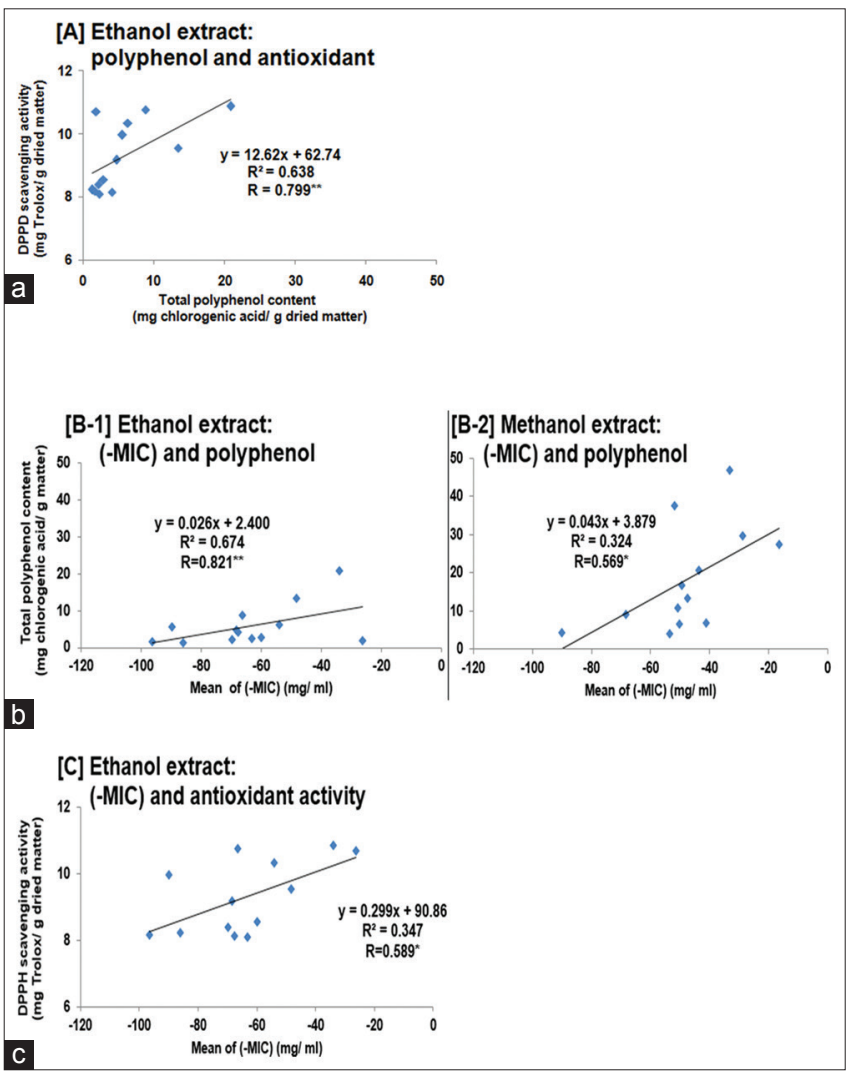

Fig. 6: (A) Linear regression and Pearson's coefficient value between polyphenol contents (mg chlorogenic acid/g dried matter) and antioxidant activities (mg Trolox/g dried sample) of ethanol extracts. (B) Linear regression and Pearson's coefficient value between mean of -minimum inhibitory concentrations (-MIC) $(\mathrm{mg} / \mathrm{ml})$ and polyphenol content (mg chlorogenic acid/g dried matter) of (B-1) ethanol and (B-2) methanol extracts. (C) Linear regression and Pearson's coefficient value between mean of -MIC (mg/ml) and antioxidant activity (mg Trolox/g dried sample) of ethanol extracts.* Significant correlation, $p<0.05$, **Significant correlation, $\mathbf{p}<\mathbf{0 . 0 1}$. All linear regressions were computed based on $n=13$ pairs of $X$ and $Y$ pharmacological basis for their therapeutic uses in diseases associated with bacterial infections [4a-g, 5a-k, 6]. In our study, Gram-positive bacteria were more sensitive to plant effects than Gram-negative bacteria, and the result was in accordance with a number of the previous reports [7]. The difference in sensitivity of the two bacterial grams to antimicrobial agents, including the plant materials, is usually explained through the significant difference in their outer layers because only Gram-negative bacteria have a thick liposaccharide coated cell wall structure [7]. Among all of tested plant samples, betel and turmeric mother rhizome showed the outstanding effects on both of Grampositive and Gram-negative bacteria, and they always represented the highest inhibitions regardless of the tested bacterial grams. Other plant materials, such as turmeric first daughter rhizome and Wedelia, also exerted good inhibition, but their effects were selectively high on only Gram-positive bacteria. Since Gram-negative bacteria are known to have stronger resistance to plant components than Gram-positive ones [14], the advantages of betel and turmeric mother rhizome to show the strongest inhibitions on Gram-negative bacteria indicated that they are the most promissory candidates for the treatment of bacterial infections. These results are in accordance with the previous studies, which have reported the high antibacterial properties of betel [15] and turmeric [16]. In addition, as these two plants are demonstrated to show positive effects on immunosystems $[17,18]$ and enhance product qualities of domestic animals $[19,20]$, it is possible to speculate their potential to become the new safe therapies for bacterial diseases. However, future researches examining betel and turmeric mother rhizome's effects in pathological conditions are still required to verify their in vivo treatment and further assess their safety.

Based on results with 12 JVPA bacteria, which had determined that betel and turmeric mother rhizome were those of the highest antibacterial effects among all tested materials, we then further examined their potentials on E. coli and S. suis bacterial strains, which had been isolated from livestock answered resistant to from at least one to four common applied antibiotics (Supplemental Material). The results showed that extracts from the two plant materials also inhibited those bacteria. Effects of betel and turmeric found on E. coli bacteria are in accordance with the previous studies $[21,22]$ and thus further confirming their therapeutic potentials for infections. Even researchers have investigated the effects of betel and turmeric on a number of bacteria [21,22], this study represented the first attempt to examine these two plants on $S$. suis strains. For the first time, inhibitory effects of betel and turmeric on $S$. suis bacteria have been demonstrated, and therefore suggesting 
that they have therapeutic potentials for $S$. suis diseases. We also observed that while betel showed significant stronger inhibition on E. coli, turmeric mother rhizome exerted significant stronger inhibition on S. suis. Comparing to other medicinal plants, betel has been reported to have significantly higher inhibition on E. coli bacteria [22], and our results further confirmed its promissory potential for the treatment of E. coli. On the other hand, turmeric mother rhizome showed higher effects than betel on $S$. suis strains. Even there has been no study directly investigating the effects of turmeric on S. suis; its rhizome has been employed as a component in one propolis composition, which had been made based on traditional herbalism and was clinically proved to show good treatment on swine $S$. suis infectious diseases [23]. While the contribution of turmeric compound in the treatment of this propolis composition remained to be verified, our study has demonstrated the high effects of turmeric on $S$. suis bacterial strains isolated from pigs and thus providing an evidence to support its use in swine S. suis diseases [23]. However, further researches on the effects of turmeric with this bacterial species are still needed to establish the treatment therapy. In our study, the inhibitory effects of betel and turmeric mother rhizome have been demonstrated on E. coli and S. suis strains that had already been resistant to antibiotics and thus indicating their potentials to alternate antibiotics in bacterial infections, especially when resistance to antibiotics had occurred and reduced antibiotic effects. The results were similar to the previous studies, which established betel and turmeric as an alternative source of anti-infective agents against multiple drug-resistant bacteria [24] and thus further added evidenced to highlight their potentials. In addition, because E. coli and S. suis are the two important bacteria which infect both animals and human, and their antibiotic resistance has been reported to be severe worldwide $[25,26]$, we believe that it is worth to research more about the effects of betel and turmeric mother rhizome with these two bacteria. Followup study which investigates the in vivo treatment of these two plants has been recently conducted in our laboratory (Department of Plant Biotechnology, Faculty of Biotechnology, Vietnam National University of Agriculture, Trau Quy crossing, Gia Lam district, Hanoi, Vietnam. Research funded by Vietnamese National Research Project on Medicinal Plants. Code: ĐTĐL CN-52/15), and future results are expected to provide more evidence and support their uses as new antibacterial therapies, which might provide the cheap and safe remedy for both human and animal health problems [27].

As polyphenol contents and antioxidant activities in plants have been demonstrated to exert many biological properties including the antimicrobial effects, our study also measured these values and investigated their relationships with the antibacterial effects. First, we analyzed the relationships between polyphenol contents and antioxidant activities and observed that they were significantly and positively correlated in extracts from methanol, but not in extracts from ethanol. Our results, therefore, on the one hand, indicated the contribution of polyphenols in plant antioxidant activities, but on the other hand, suggested that these activities were not only solely limited to polyphenols but also derived from other compounds. While phenols have been considered as main plant antioxidant components and their direct proportion to antioxidant activities was well established [28], researchers have also suggested that other secondary metabolites in plants, such as volatile oils, carotenoids, vitamins, or botanical polysaccharides, also play a role in their antioxidant activities $[29,30]$. When comparing the results of polyphenol contents with the results of antibacterial effects, our study found that the plants which represented the highest effects on bacteria, including betel and turmeric mother rhizome, were also represented the highest values of polyphenol contents. However, their antioxidant activities were not as remarkable because the similar high activity values were also observed in other plants such as culantro, greater plantain, and turmeric first daughter rhizome. These results suggested that antibacterial effects might be more closely associated with polyphenol contents than with antioxidant activities. The hypothesis was further evident with the next results, which showed that while correlations between - MICs and polyphenol contents were always positive and significant regardless of the extracting solvents, correlations between - MICs and antioxidant activities were less evident, as they were not significant in methanol extracts. Considering these results overall, it is possible to speculate that phenolic compounds are an important factor that directly contributes to antibacterial effects of the plants investigated in our study, and this is in accordance with a number of the previous studies, which reported that phenolic was the most important active compound against bacteria in plants [7]. The proportion of phenolic compounds in antibacterial effects of plants also partly explained the difference insensitivities between the two bacterial grams that observed with this study. Since only Gram-negative bacteria have a thick liposaccharide coated cell wall that impermeable to polar phenolic acids [31], they are more resistant than Gram-positive bacteria to polyphenol compounds and thus more resistant to plant effects. Polyphenol compounds have been reported to exert many pharmacological functions, including the antibacterial effects, through their antioxidant activities [9]. However, in our study, the correlations of antioxidant activities with antibacterial effects were less evident than those of polyphenol contents. It can be explained through the fact that some polyphenols, such as tannins, might exert antibacterial effects through pathways that different from antioxidant modes of action [32]. In addition, the chemical structures, but not antioxidant activities, are known to be more responsible in antimicrobial properties of some plant active components [32,33]. These reasons might partly explain the less significant correlations between antioxidant activities and antibacterial effects observed in this study, and indicate that investigation on pathways that different from antioxidant mode of actions is still required to verify the effects. In addition, because our study evaluated antibacterial effects of plants through MICs, the values that represented only the direct inhibition on bacteria, we were not able to access the other indirect pathways, which are also known to play a role in the treatment of plants with bacteria [34]. Since bacterial infections induce the oxidative stress [34], researchers have demonstrated that the antibacterial effects of plants are not only mediated through their direct inhibition on bacterial agents but also through the indirect inhibition, such as the antioxidant activities to reduce cellular damage caused by oxidative stress [35]. As our study has not yet examined these indirect pathways, we were not able to access in the full scale the role of antioxidant activities in plant antibacterial effects, and future researches with in vivo study would, therefore, be necessary to verify this point.

In our results, it was noticeable that turmeric mother rhizome showed significantly stronger inhibition on bacteria than the first daughter rhizome. Even some studies have indicated that different types of turmeric rhizome might contain different concentrations of active compounds, including curcumin, the main active component of turmeric [36], there have been no reports investigated the difference in their pharmacological properties. In addition, researches that separated mother rhizome and first daughter rhizome of turmeric to examine have been mainly focusing on only comparing their seeding effects [37]. Interestingly, our study found that they were also different in antibacterial properties because mother rhizome was significantly stronger than first daughter rhizome in the inhibitory effects with bacteria. This difference was then partly attributed to the polyphenol contents and antioxidant activities because the former was also superior in the values represented these properties. Considering the results overall, our study has demonstrated that mother rhizome is a more advantageous rhizome type of turmeric not only in effects with bacteria but also in other properties such as polyphenols or antioxidants. This finding partly gives pharmacological basis to explain why traditional healers had observed the superior of turmeric mother rhizome to turmeric daughter rhizome in the treatment of some diseases including those are associated with bacterial infections [10]. Furthermore, the results indicate that future researches into pharmacological effects or phytochemical constituents of turmeric should separate its rhizome types and investigate because it is likely that they have different properties. However, the isolation and characterization of active compounds that responsible for their difference is still in progress and will be underway on future researches.

In our study, both extracts from ethanol and methanol showed inhibitory effects on tested bacteria. As stated by Cowan [38], nearly all of the identified components from plants active against microorganisms are aromatic or saturated organic compounds and are most often obtained through initial 
ethanol or methanol extraction. In our study, solvents also played a role in extract biological values because those from methanol yielded the significantly stronger antibacterial effects and were also richer in polyphenol contents. These results are in accordance with some studies [39], while they are in opposite with others $[40,41]$. The diverse in biological activities of plant extracts from different solvents is explained by the differences in their degrees of solubility for various phytochemicals [38]. Therefore, in research with medicinal plants, the optimization study on extracting solvents is necessary, as they lead in the selection of suitable solvents for each plant material and each target property [42].

\section{CONCLUSIONS}

Our study has demonstrated the antibacterial effects of 13 plant materials, which partly gives the pharmacological basis to explain their traditional uses for the treatment of diseases associated with bacterial infections. Antibacterial effects of those plant extracts were closely correlated to their polyphenol contents, suggesting that these compounds play a significant role in the effects of plants on bacteria. Among all tested plant materials, betel and turmeric mother rhizome showed the highest antibacterial effects, and they also exerted inhibition on E. coli and S. suis strains that had already been resistant to antibiotics, suggesting that they might be the promissory candidates to alternate antibiotic uses in bacterial infections.

\section{CONFLICTS OF INTEREST}

None of the authors have any competing interest to declare.

\section{ACKNOWLEDGMENTS}

We are grateful to Dr. Tho Thi Bui for identification of plant samples.

\section{AUTHORS' CONTRIBUTIONS}

Dr. Thanh Van Nguyen and Dr. Hai Thanh Nguyen were the primary investigator in this study. Dr. Thanh Van Nguyen performed the investigation on plant antibacterial effects. Dr. Hai Thanh Nguyen performed the investigation on plant biological values, such as polyphenol contents and antioxidant effects, and also examined their relationships with antibacterial properties. Dr. Thanh Van Nguyen designed the study and wrote the manuscript as corresponding author.

\section{APPENDIX A. SUPPLEMENTARY DATA}

Supplementary data associated with this article can be found in the "Supplemental Material."

\section{REFERENCES}

1. Rojas R, Bustamante B, Bauer J, Fernandez I, Alban J, Lock O. Antimicrobial activity of selected Peruvian medicinal plants. J Ethnopharmacol 2003;88:199-204.

2. Mahesh B. Satish S. Antimicrobial activity of some important medicinal plant against plant and human pathogens. World J Agric Sci 2008;4:839-43.

3. Immanuel G, Vincybai VC, Sivaram V, Palavesam A, Marian MP. Effect of butanolic extracts from terrestrial herbs and seaweeds on the survival, growth and pathogen (Vibrio parahaemolyticus) load on shrimp Penaeus indicus juveniles. Aquaculture 2004;236:53-65.

4. Le VT, Nguyen GC. Selected Medicinal plants in Vietnam. Volume I, II 1999. Vietnam National Institute of Materia Medica Publications. Science and Technology Publishing house, Hanoi, Vietnam. (a): Artemisia vulgaris L. - Asteraceae. In: Le, V.T. and Nguyen, G.C. (eds.), Volume I, pp. 99-103. (b): Curcuma domestica Valet. - Zingiberaceae. In: Le, V.T. and Nguyen, G.C. (eds.), Volume I, pp. 263-268; 1999. (c): Paederia foetida L. - Rubiaceae. In: Le, V.T. and Nguyen, G.C. (eds.), Volume II, pp. 161-164. (d): Piper betle L. - Piperaceae. In: Le, V.T. and Nguyen, G.C. (eds.), Volume II, pp. 179-182. (e): Plantago major L. - Plantaginaceae. In: Le, V.T. and Nguyen, G.C. (eds.), Volume II, pp. 184-189. (f): Pluchea indica (L.) Less. - Asteraceae. In: Le, V.T. and Nguyen, G.C. (eds.), Volume II, pp. 189-192. (g): Wedelia calendulacea Less. - Asteraceae. In: Le, V.T. and Nguyen, G.C. (eds.), Volume II, pp. 357-361.
5. Do, T.L. Nhung cay thuoc va vi thuoc thuong dung tai Vietnam. [Book in Vietnamese]. Hanoi, Vietnam: Vietnam Medical Publishing House; 2005. (a): Cuc Tan. Pluchea indica. In: Do, T.L. (eds.), pp. 685-686. (b): Gung gio. Zingiber zerumbet. In: Do, T.L. (eds.), pp. 368-369. (c): Hung que. Ocimum basilicum L. var. basilicum. In: Do, T.L. (eds.), pp. 659-660. (d): Ma de. Plantago asiatica L. In: Do, T.L. (eds.), pp. 215-217. (e): Mo tam the. Paederia tomentosa L. In: Do, T.L. (eds.), pp. 186-187, 2005. (f): Ngai cuu. Artemisia vulgaris L. In: Do, T.L. (eds.), pp. 36-37. (g): Nghe. Curcuma longa L. In: Do, T.L. (eds.), pp. 227-230. (h): Rau Mui Tau. Eryngium foetidum L. In: Do, T.L. (eds.), pp. 687-688. (i): Sai dat. Wedelia calendulacea L. In: Do, T.L. (eds.), pp. 86-88. (j): Thia la. Anethum graveolens L. (Peucedanum graveolens Benth). In: Do, T.L. (eds.), pp. 422-423. (k): Trau khong. Piper betle L. In: Do, T.L. (eds.). pp: 118-119.

6. Balekar N, Nakpheng T, Srichana T. Wedelia trilobata L.: A phytochemical and pharmacological review. Chiang Mai J Sci 2014;41:590-605.

7. Shan B, Cai YZ. The in vitro antibacterial activity of dietary spice and medicine herb extracts. Int J Food Microbiol 2007;117:112-9.

8. Singh K, Tafida GM. Antibacterial activity of Moringa oleifera (Lam) leaves extracts against some selected bacteria. Int J Pharm Pharm Sci 2014;6:52-4.

9. Pandey KB, Rizvi SI. Plant polyphenols as dietary antioxidants in human health and disease. Oxid Med Cell Longev 2009;2:270-8.

10. Bui TT. Curcuma longa. [Document in Vietnamese]. In: Bui TT, editor. Phuong phap nghien cuu cay thuoc-Tai lieu tham khao cho cac nghien cuu thuc nghiem ve cay thuoc (luu hanh noi bo trong phong thi nghiem Duoc Ly Thu Y). Department of Internal Medicine and Pharmacology, Faculty of Veterinary Medicine. Hanoi, Vietnam: Vietnam National University of Agriculture; 2012. p. 18-9.

11. Japanese Society of Antimicrobials. Revision of the Determination Method of the Minimum Inhibitory Concentration (MIC) of Antimicrobials Against Bacteria Isolated from Animals. The Committee for Standardization of MIC Determination Method. Vol. 25. In: Proceeding of the Japanese Society of Antimicrobials for Animals; 2003. p. 63-73.

12. Clinical and Laboratory Standards Institute. National Committee for Clinical Laboratory Standards (NCCLS). Approved standard M11-A2: Methods for Antimicrobial Susceptibility Testing of Anaerobic Bacteria. Villanova, PA: NCCLS; 1990.

13. Masuda T, Oyama Y, Inaba Y, Toi Y, Arata T, Takeda Y, et al. Antioxidant related activities of ethanol extracts from edible and medicinal plants cultivated in Okinawa, Japan 2002. Nippon Shokuhin Kagaku Kogaku Kaishi 2002;49:652-61.

14. Lawson LD. Garlic: A review of its medicinal effects and indicated active compounds. In: Lawson LD, Bauer R, editors. Phytomedicines of Europe: Their Chemistry and Biological Activity. Washington DC: ASC Press; 1996. p. 176-200.

15. Hong X, Lu L, Xu D. Progress in research on acute hepatopancreatic necrosis disease (AHPND). Aquaculture Int 2016;24:577-93.

16. Niamsa N, Sittiwet C. Antimicrobial activity of Curcuma longa aqueous extract. J Pharmacol Toxicol 2009;4:173-7.

17. Kanjwani DG, Marathe TP, Chiplunkar SV, Sathaye SS. Evaluation of immunomodulatory activity of methanolic extract of Piper betel. Scand J Immunol 2008;67:589-93.

18. Malar HL, Charles PM. Effect of turmeric Curcuma longa Linn extract on immunity and resistance to Vibrio harveyi in black tiger shrimp Penaeus monodon. Int J Zool Res 2013;3:21-6.

19. Lagana C, Pizzolante CC, Saldanha ES, Moraes JE. Turmeric root and annato seed in second-cycle layer diets: Performance and egg quality. Rev Bras Ciênc Avíc 2011;13:171-6.

20. Rahardja DP, Hakim MR, Lestari VS. Egg production performance of old laying hen fed dietary turmeric powder. Int J Biol Biomol Agric Food Biotechnol Eng 2015;9:748-52.

21. Negi PS, Jayaprakasha GK, Rao LJ, Sakariah KK. Antibacterial activity of turmeric oil: A byproduct from curcumin manufacture. J Agric Food Chem 1999;47:4297-300.

22. Sivasankaridevi T, Rajan SA, Maina CC, Suvarna VC. Antimicrobial activity of some important edible leaf extracts. Insight Microbiol 2013;3:15-8.

23. Fu Z, Liu WA. Compound Propolis Composition for Treating Swine Streptococcicosis and Preparation Method Thereof. Patent CN No. 102430098; 2013.

24. Teow SY, Liew K, Ali SA, Khoo AS, Peh AC. Antibacterial action of curcumin against Staphylococcus aureus: A brief review. J Tropical Med 2016;2016:10.

25. Bell JM, Turnidge JD, Gales AC, Pfaller MA, Jones RN. Sentry APAC study group. Prevalence of extended spectrum beta-lactamase (ESBL)producing clinical isolates in the Asia-Pacific region and South Africa: 
Regional results from SENTRY. Antimicrobial surveillance program (1998-9). Diagn Microbiol Infect Dis 2002;42:193-8.

26. Palmieri C, Varaldoand PE, Facinelli B. Streptococcus suis, an emerging drug-resistant animal and human pathogen. Front Microbiol 2011;2:235

27. Da Silva LI, Karuppusamy A, Miyajima F, Violante IM, Bieski IG, Balogun SO, et al. Antimicrobial and antioxidant activities of selected plants used by populations from Juruena valley, legal amazon, Brazil. Int J Pharm Pharm Sci 2017;9:179-91.

28. Liu SC, Lin JT, Wang CK, Chen HY, Yang DJ. Antioxidant properties of various solvent extracts from lychee (Litchi chinenesis Sonn.) flowers. Food Chem 2009;115:577-81.

29. Javanmardi J, Stushnoff C, Lockeb E, Vivancob JM. Antioxidant activity and total phenolic content of Iranian Ocimum accessions. Food Chem 2003;83:547-50

30. Ravipati AS, Zhang L, Koyyalamudi SR, Jeong SC, Reddy N, Bartlett J, et al. Antioxidant and anti-inflammatory activities of selected Chinese medicinal plants and their relation with antioxidant content. BMC Complement Altern Med 2012;12:173.

31. Chakraborty A, Mandal SM, Chakraborty J, Bhattacharyaa PK, Bandyopadhyay A, Mitra A, et al. Antimicrobial activities of leaf extract of Basilicum polystachyon (L) Moench. Ind J Exp Biol 2007;45:744-8.

32. Duda-Chodak A, Tarko T, Statek M. The effect of antioxidants on Lactobacillus casei cultures. Acta Sci Pol Technol Aliment 2008;7:39-51.

33. Sharma V, Rao LJ. A thought on the biological activities of black tea. Crit Rev Food Sci Nutr 2009;49:379-404

34. Chakraborty SP, Mahapatra SK, Sahu SK, Das S, Tripathy S, Dash S, et al. Internalization of Staphylococcus aureus in lymphocytes induces oxidative stress and DNA fragmentation: Possible ameliorative role of nanoconjugated vancomycin. Oxid Med Cell Longev 2011;94:21-3.

35. Mothana RA, Lindequist U. Antimicrobial activity of some medicinal plants of the Island soqotra. J Ethnopharmacol 2005;96:177-81.

36. Kobayashi T, Miyazaki A, Matsuzawa A, Kuroki Y, Shimamura T, Yoshida $\mathrm{T}$, et al. Change in curcumin content of rhizome in turmeric and yellow zedoary. Jan J Crop Sci 2010;1:10-5.

37. Hossain A, Ishimine Y, Akamine H, Motomura K. Effects of seed rhizome size on growth and yield of turmeric (Curcuma longa L.). Plant Prod Sci 2005;8:86-94

38. Cowan MM. Plant products as antimicrobial agents. Clin Microbiol Rev 1999;12:564-82.

39. Lee JH, Cho S, Paik HD, Choi SW, Nam KT, Hwang SG, et al. Investigation on antibacterial and antioxidant activities, phenolic and flavonoid contents of some Thai edible plants as an alternative for antibiotics. Asian Australas J Anim Sci 2014;10:1461-8

40. Sen A, Batra A. Evaluation of antimicrobial activity of different solvent extracts of medicinal plant: Melia Azedarach L. Int J Curr Pharm Res 2012;4:67-73.

41. Do QD, Angkawijaya AE, Tran-Nguyen PL, Huynh LH, Soetaredjo FE, Ismadji S, et al. Effect of extraction solvent on total phenol content, total flavonoid content, and antioxidant activity of Limnophila aromatic. J Food Drug Anal 2014;22:296-302.

42. Azwanida NN. A review on the extraction methods use in medicinal plants, principle, strength and limitation. Med Aromat Plants 2015;4:196. 


\section{SUPPLEMENTAL MATERIAL}

Frequencies of antimicrobial resistance in Escherichia coli isolated from chicken feces

\begin{tabular}{lll}
\hline Antimicrobial & Breakpoint $\mathbf{( M g / m l )}$ & $\begin{array}{l}\text { Number of resistant } \\
\text { isolates } \mathbf{( \% )}\end{array}$ \\
\hline Ampicillin & 32 & $9(100.0)$ \\
Chloramphenicol & 32 & $3(33.3)$ \\
Chlortetracycline & 16 & $2(77.8)$ \\
Nalidixic acid & 32 & $3(33.3)$ \\
Streptomycin & 32 & $5(55.5)$ \\
Sulfadimethoxine & 512 & $9(100.0)$ \\
\hline
\end{tabular}

Numbers in parenthesis indicate the percentage

Phenotypes of antimicrobial resistance of nine Escherichia coli strains isolates from chicken feces

CTC-CP-STR-NA-SDM

CP-STR-NA-SDM

CTC-NA-SDM

$1(11.1)$

cp-smsDM

$1(11.1)$

SDM-STEL

$1(11.1)$

SDM

$3(33.3)$

Resistance 9 (100)

Numbers in parenthesis indicate the percentage. (a) CHL: Chloramphenicol, CTC: Chlortetracycline, STR: Streptomycin, NAL: Nalidixic acid,

SDM: Sulfadimethoxine. (b) Breakpoints suggested by the Clinical and

Laboratory Standards Institute ${ }^{[1]}$ were used for the determination of resistance

to CHL (32 $\mu \mathrm{g} / \mathrm{ml})$, CTC ( $16 \mu \mathrm{g} / \mathrm{ml})$, NAL $(16 \mu \mathrm{g} / \mathrm{ml})$, and SDM $(512 \mu \mathrm{g} / \mathrm{ml})$. The

breakpoint of STR was $32(\mu \mathrm{g} / \mathrm{ml})$, as described by Orden et al. [2]

Frequencies of antimicrobial resistance in 23 Streptococcus suis strains isolated from pigs

\begin{tabular}{lll}
\hline Antibiotic & Breakpoint $(\boldsymbol{\mu g} / \mathbf{m l})$ & $\begin{array}{l}\text { Number of resistant } \\
\text { isolates }(\%)\end{array}$ \\
\hline Ampicillin & 0.5 & $0(0.0)$ \\
Chlortetracycline & 8 & $23(100.0)$ \\
Kanamycin & 250 & $3(13.0)$ \\
Penicillin & 0.25 & $0(0.0)$ \\
Sulfadimethoxine & 512 & $23(100.0)$ \\
Streptomycin & 250 & $5(21.7)$ \\
\hline
\end{tabular}

Numbers in parenthesis indicate the percentage
Phenotypes of antimicrobial resistance of 23 Streptococcus suis strains isolated from pigs

\begin{tabular}{ll}
\hline Resistance phenotype & Number of resistant isolates (\%) \\
\hline CTC-KAN-SDM-STR & $1(4.3)$ \\
CTC-KAN-SDM & $2(8.7)$ \\
CTC-S1R-STR & $4(17.4)$ \\
CTC-SDM & $16(69.6)$ \\
Resistance & 100 \\
\hline
\end{tabular}

Numbers in parenthesis indicate the percentage. CTC: Chlortetracycline, KAN: Kanamycin, SDM: Sulfadimethoxine, STR: Streptomycin. Breakpoints suggested by the Clinical and Laboratory Standards Institute[1] were used for the determination of resistance to CTC $(8 \mu \mathrm{g} / \mathrm{ml})$ and SDM $(512 \mu \mathrm{g} / \mathrm{ml})$. The breakpoints of KAN and STR were $250(\mu \mathrm{g} / \mathrm{ml})$, followed the guidelines or manufacturers[3]

\section{REFERENCES FOR SUPPLEMENTAL MATERIAL}

1. Clinical and Laboratory Standards Institute. Performance Standards for Antimicrobial Susceptibility Testing: $17^{\text {th }}$ Information Supplement, CLSI Document M100-S17. Wayne, PA: Clinical and Laboratory Standard Institute; 2007.

2. Orden JA, Santa-Quiteria JA, Carcia S, Cid D, La Fuente RD. In vitro susceptibility of Escherichia coli strains isolated from diarrhoeic dairy calves to 15 antimicrobial agents. J Vet Med B Infect Dis Vet Public Health 2000;47:329-35.

3. Marie J, Morvan H, Berthelot-Herault F, Sanders P, Kempf I, GautierBouchardon AV, et al. Antimicrobial susceptibility of Streptococcus suis isolated from swine in France and from humans in different countries between 1996 and 2000. J Antimicrob Chemother 2002;50:201-9. 